\section{Determination of Nitrogen in Proteins by means of Indanetrione Hydrate}

The determination of nitrogen in organic substances has been performed by either of the well-established methods, namely, one attributed to Dumas or the other first described by Kjeldahl. These methods require approximately $300 \mu \mathrm{gm}$. of nitrogen for accurate determination. The method to be described requires much less material, and compares favourably in accuracy with these standard methods. The sample is decomposed by digestion in sulphuric acid, and the ammonia is determined quantitatively by means of indanetrione hydrate.

The sample (for example, $0.05-0.10 \mathrm{ml}$. serum) is digested in $0.5-1.0 \mathrm{ml}$. sulphuric acid to which is added 3-5 mgm. of a mixture of copper sulphate (microanalytical reagent), potassium sulphate (microanalytical reagent), mercuric oxide (laboratory grade) and selenium (5:15:5:1 parts by weight respectively). The sample is heated in a standard Kjeldahl flask for 45 min., when it should have cleared. If the acid digest is not clear after 45 min., the flask is cooled, $0.2 \mathrm{ml}$. of hydrogen peroxide solution (100 vol. B.D.H., microanalytical reagent) is added drop by drop and the contents of the flask are re-heated. The solution becomes clear immediately and the heating is continued for $2 \mathrm{hr}$.

The digested sample is dissolved in $0.4 M$ sodium eitrate buffer solution $p . \mathrm{H} .5 \cdot 0(25 \mathrm{ml}$. buffer solution for $0.5 \mathrm{ml}$. sulphuric acid : $50 \mathrm{ml}$. buffer solution for $1.0 \mathrm{ml}$. sulphuric acid). An aliquot, normally $0.5 \mathrm{ml}$., of this solution, diluted further if necessary with buffer solution to make $2.0 \mathrm{ml}$., is mixed with $2.0 \mathrm{ml}$. of a 2 per cent indanetrione hydrate solution. $(2 \cdot 0 \mathrm{gm}$. indanetrione hydrate : $50 \mathrm{ml}$. methyl 'Cellosolve': $25 \mathrm{ml} .4 .0 \mathrm{M}$ sodium acetate buffer solution $p \mathrm{HI} 5 \cdot 5$ $(544 \mathrm{gm}$. sodium acetate trihydrate $+100 \mathrm{ml}$. glacial acetic acid per litre): $25 \mathrm{ml}$. water : $0.08 \mathrm{gm}$. stannous chloride dihydrate (analytical reagent).) The mixture is heated in a water bath at $100^{\circ} \mathrm{C}$. for $30 \mathrm{~min}$., cooled and diluted with $6 \mathrm{ml}$. of a solution of ethanol/water ( $1: 1$ by volume).

When determined in a Uvispek spectrophotometer, a solution containing $0.4 \mu M$ of ammonia $(=5 \cdot 6 \mu \mathrm{gm}$. nitrogen) has an optical density of $0.805( \pm 0.008)$ for $1 \mathrm{~cm}$. path-length at a wave-length of $570 \mathrm{~m} \mu$. The optical density of the control solution, that is, $1.0 \mathrm{ml}$. sulphuric acid (microanalytical reagent) diluted in the same manner, varies between $0 \cdot 045$ and $0 \cdot 060$.

Column 1 of Table 1 shows typical analyses of a serum from a normal rhesus monkey performed by the indanetrione hydrate method. Column 2 shows analyses of the same serum by the standard micro-Kjeldahl method.

\begin{tabular}{|c|c|}
\hline \multicolumn{2}{|c|}{ Table 1} \\
\hline Indanetrione hydrate & Micro-Kjeldahl \\
\hline $\begin{array}{l}11 \cdot 3 \text { mgm. N per ml. } \\
11 \cdot 3 \\
11 \cdot 4\end{array}$ & $\begin{array}{l}11 \cdot 3 \mathrm{mgm} . \mathrm{N} \text { per } \mathrm{ml} . \\
11 \cdot 4 \\
11 \cdot 3\end{array}$ \\
\hline
\end{tabular}

The method has been used for routine purposes and is found to be more reliable than the standard micro-Kjeldahl method. The aliquot, examined in triplicate if necessary, contains only one-fiftieth or onehundredth part of the original nitrogen. Work is in progress to apply this method to the quantitative determination of nitrogen in other nitrogenous compounds following their digestion in sulphuric acid.

The indanetrione hydrate may be purified without loss by the method already described ${ }^{1}$. The presence of traces of cations in the digest solution, due to the catalyst, does not affect the colour development (cf. Meyer and Riklis ${ }^{2}$ ) during the reaction between the ammonia and the indanetrione hydrate. Wherever possible, analytical reagents are used and all solutions are prepared with conductivity water obtained by de-ionizing once-distilled water ${ }^{3}$. In our experience the analytical reagent most likely to produce high values of optical density with the control solution is sodium acetate: but this compound may be easily purified by re-crystallization from ethyl alcohol to yield satisfactory value: of optical density with the control solution.

National Institute for Misdical Research,

$$
\text { S. JACOBS }
$$
Mill Hill, London, N.W.7.

${ }^{1}$ Jacobs, S., Analyst, 81, 502 (1956)

${ }^{2}$ Meyer, H., and Riklis, E., Nature, 172, 543 (1953).

${ }^{3}$ Jacobs, S., Chem. and Indust., 944 (1955).

\section{Replacement of Thiamine as a Growth Factor for Mycobacterium butyricum}

Thiamine is recognized as a growth factor for many micro-organisms. Some micro-organisms require the presence of the whole thiamine molecule whereas others are able to synthesize either the pyrimidine or thiazole moieties. In some instances, cells are unable to use either component, but if supplied with the two fragments can combine the two into the complete molecule. Pyrithiamine (1-[(4-amino-2-methyl)-5pyrimidylmethyl]-2-methyl-3 ( $\alpha$-hydroxyethyl) pyridinium bromide) is a thiamine analogue in which a pyridine ring replaces the thiazole moiety. This analogue has an anti-thiamine effect in some microorganisms, and in others it can replace thiamine by acting as a source of the pyrimidine ring ${ }^{1,2}$.

Thiamine is required for the growth of $M y c o$. bacterium butyricum in chemically defined media ${ }^{3}$. This requirement has been examined by growing M. butyricum (No. 337, National Collection of Type Cultures, Lister Institute, London) on a synthetic medium containing inorganic salts with glycerol as a carbon source and ammonium sulphate as a nitrogen source. To this medium was added thiamine hydroehloride, 4-amino-5-aminomethyl 2-methyl pyrimidine 2 hydrochloride, 5-(2-hydroxyethyl) 4-methyl thiazole, or pyrithiamine. The medium was sterilzed by autoclaving at $15 \mathrm{lb}$. for $15 \mathrm{~min}$. The flasks (500 ml.) containing $100 \mathrm{ml}$. of medium were inoculated with a washed suspension of cells $(0.4 \mathrm{mgm}$. dry wt.) and the cultures incubated aerobically at $38^{\circ}$ for nine days. Growth was estimated by filtering off the cells, washing well with distilled water and drying at $105^{\circ}$ in weighed crucibles.

Only a slight growth was observed in the absence of thiamine or with the thiazole fragment (Table 1). Good growth occurred with thiamine, with the pyrimidine moiety, with the pyrimidine plus thiazole moieties, or with pyrithiamine. Since the pyrimidine fragment seems to be essential for growth, it was considered possible that pyrithiamine was exerting its effect due to hydrolysis on autoclaving. This was tested by adding to the growth medium pyrithiamine sterilized by autoclaving or by filtering through a glass filter (porosity 5), or by adding directly from its bottle to the sterile medium. No difference was noted in the growth response to autoclaved, filtered or unsterilized pyrithiamine.

These results demonstrate the inability of $M$. butyricum to synthesize the pyrimidine moiety of thiamine at a sufficient rate to promote normal 